\title{
Chromatographic Methods for Determination of Finasteride and Tamsulosin Hydrochloride and in Presence of Finasteride Degradation Product
}

\author{
Hany H. Monir ${ }^{1 *}$, Alshimaa M. Ali ${ }^{2}$, Rawnaa E. Refat ${ }^{2}$ and Samah S. Abbas ${ }^{1}$ \\ ${ }^{2}$ Analytical Chemistry Department, Faculty of Pharmacy, Cairo University, Kasr El-Aini Street, 11562, Cairo, Egypt \\ ${ }^{2}$ National Organizations for Drug Control and Research, Wezaret El-Zeraa Street, Cairo, Egypt
}

Received: 27 November 2018; accepted: 08 February 2019

\begin{abstract}
Two sensitive and selective chromatographic methods were developed for determination of finasteride and tamsulosin hydrochloride in bulk powder and a pharmaceutical formulation. The first method was based on high-performance liquid chromatography (HPLC) separation of the cited drugs in the presence of the acid degradation product of finasteride. The separation was achieved using a C18 column $(300 \mathrm{~mm} \times 3.9 \mathrm{~mm} ; 10-\mu \mathrm{m}$ particle size $)$ and a mobile phase consisting of $0.04 \mathrm{M}$ ortho-phosphoric acid ( $\mathrm{pH} 3.5 \pm 0.2$ adjusted with triethylamine) and acetonitrile $(50: 50, v / v)$. Quantification was achieved with ultraviolet (UV) detection at $215 \mathrm{~nm}$. Linearity was in the range of $10.00-110.00 \mu \mathrm{g} / \mathrm{mL}$ and $2.00-44.00 \mu \mathrm{g} / \mathrm{mL}$ for finasteride and tamsulosin hydrochloride, respectively. Thinlayer chromatography (TLC)-densitometric method was achieved on an aluminum plates pre-coated with silica gel $60 \mathrm{~F}_{254}$ using toluene-ethanol-diethylamine ( $8: 2: 1.5$, by volume) as eluent, and the $R_{\mathrm{F}}$ values of tamsulosin hydrochloride and finasteride were 0.57 and 0.64 , respectively. Quantification was achieved with UV detection at $250 \mathrm{~nm}$ for finasteride and $280 \mathrm{~nm}$ for tamsulosin hydrochloride. Linearity was in the range of 1.00-40.00 and 0.2.00-20.00 $\mu \mathrm{g}$ per spot for finasteride and tamsulosin hydrochloride, respectively. The results obtained were validated according to the International Conference on Harmonisation ( $\mathrm{ICH}$ ) guidelines. A statistical comparison between the obtained results and the results of a reported method was carried out.
\end{abstract}

Keywords: finasteride, Tamsulosin hydrochloride, HPLC, TLC-densitometry

\section{Introduction}

Finasteride (FIN), N-(1,1-dimethyl ethyl)-3-oxo-4-aza5androst-1-ene-17-carboxamide (Figure 1a) [1, 2], is a type II 5-alpha-reductase inhibitor, which slowly reduces prostate volume. Prostate growth and function are influenced by dihydrotestosterone, 5-alphareductase enzyme converts testosterone to dihydrotestosterone. The inhibition of 5-alphareductase results in decrease of level of dihydrotestosterone leading to reduction of prostate size [3]. Tamsulosin (TAM), 5-[(2R)-2[[2-(2ethoxyphenoxy)ethyl]amino]propyl]-2-methoxy-benzene sulfonamide (Figure 1b) [1,2] is a selective alpha-1 adrenoceptor blocking agent. Smooth muscle tone is mediated by the sympathetic nervous system. Stimulation of alpha-1 adrenoceptor can cause smooth muscles in the bladder neck and prostate to relax, resulting in an improvement in urine flow and reduction in symptoms of benign prostatic hyperplasia [3]. TAM and FIN combination results in reduction of benign prostatic hyperplasia progression to acute urinary retention. It also results in statistically significant benefits in quality of life scores patient satisfaction and urinary frequency.

A literature survey reveals that only few analytical methods such as liquid chromatography-mass spectroscopy (LC-MS) [4-6] and high-performance chromatography (HPLC) [7] were developed for determination of TAM in biological fluids and in pharmaceuticals. A few LC-MS [8-11] and HPLC $[12,13]$ methods have been reported for the determination of finasteride in biological fluids and in pharmaceuticals. Although there are reported HPLC methods [14, 15] for determination of both drugs, none of them determined FIN in the presence

\footnotetext{
*Author for correspondence: hany.hunter@pharma.cu.edu.eg; Tel: +2 1005856580.
}

of its degradation products. No thin-layer chromatography (TLC)-densitometric methods have been developed for FIN and TAM determination together. Accordingly, the aim of the present study was to develop simple rapid and sensitive stability-indicating chromatographic methods for the determination of the cited drugs.

\section{Experimental}

\subsection{Instruments.}

- HPLC Agilent model 1200 was equipped with a quaternary pump, a Rheodyne injector with a $20-\mu \mathrm{L}$ loop and ultraviolet (UV) detector (Germany). Separation and quantitation were made on Bondapak C18-AR (300 mm $\times$ $3.9 \mathrm{~mm}, 10-\mu \mathrm{m}$ particle size). The detector was set at $215 \mathrm{~nm}$. The instrument was connected to an IBM compatible PC and an HP diskjet printer.

- A pH meter HANNA 8417 (Portugal) was used.

- Shimadzu dual wave length lamp flying spot, model CS 9301PC software densitometer-UV short wavelength lamp $(254 \mathrm{~nm})$.

- Glass jars $20 \mathrm{~cm} \times 22 \mathrm{~cm} \times 10 \mathrm{~cm}$. The spots were scanned under the following conditions. Wavelength: $250 \mathrm{~nm}$ and $280 \mathrm{~nm}$ for FIN and TAM, respectively; Photo mode: reflection; Lane: auto zero; Set mode: at start; Scan mode: zigzag; Difference: off; Lambda: single; and trace: off. Hamilton $25-\mu \mathrm{L}$ syringe (USA).

- Pre-coated $20 \mathrm{~cm} \times 20 \mathrm{~cm}$ TLC aluminum sheet silica gel $\mathrm{F}_{254}$ plates, 0.2-mm thickness (Fluka, Buchs, Switzerland).

- Fourier-transform nuclear magnetic resonance (FT-NMR) spectrometer: Bruker high-performance digital FT-NMR

This is an open-access article distributed under the terms of the Creative Commons Attribution-NonCommercial 4.0 International License (https://creativecommons.org/licenses/by-nc/4.0/), which permits unrestricted use, distribution, and reproduction in any medium for non-commercial purposes, provided the original author and source are credited, a link to the CC License is provided, and changes - if any - are indicated. 


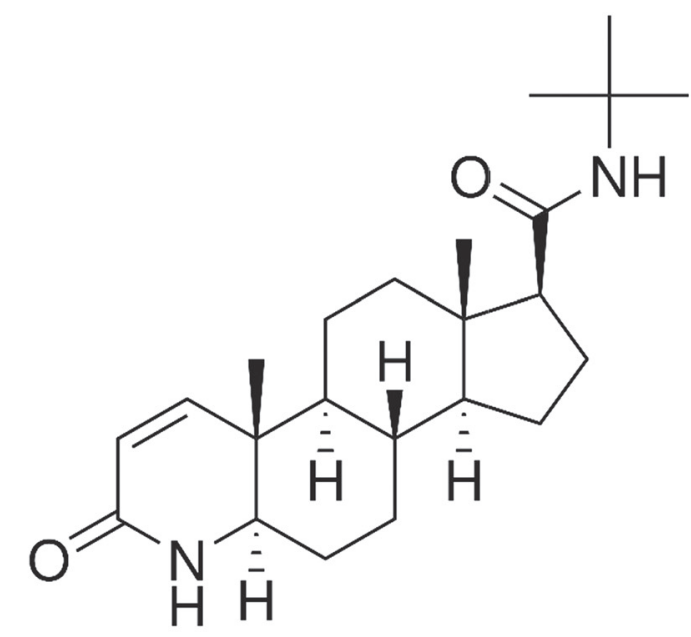

(a)<smiles>CCOc1ccccc1OCCN[C@H](C)Cc1ccc(OC)c(S(N)(=O)=O)c1</smiles>

(b)

Figure 1. Chemical structure of finasteride (a) and tamsulosin hydrochloride (b)

spectrometer Avance III $400 \mathrm{MHz}$ (Billerica, Massachusetts, United States). Fourier-transform infrared (FTIR) spectrometer: Schimatzu FTIR Affinity-1 spectrometer (Kyoto, Japan).

\subsection{Samples}

(a) Pure Standards. Finasteride standard was kindly supplied by Sigma-Aldrich; its purity was $99.30 \%$, according to the pharmacopoeia method [16].

Tamsulosin standard was kindly supplied by Al Debeiky Pharma, Egypt; its purity was $99.97 \%$, according to the pharmacopoeia method [16].

(b) Pharmaceutical Dosage Form. Urimax F (5 mg FIN, 0.4 mg TAM per capsule), manufactured by Cipla Pharmaceutical Ltd., India (B.N. A41516), was used.

2.3. Solvents and Chemicals. All solvents and chemicals used were of analytical grade.

- Phosphoric acid and acetonitrile for HPLC. The water for HPLC was prepared by double filtration through a $0.45-\mu \mathrm{m}$ membrane filter.

- Toluene, trimethylamine, concentrated hydrochloric acid, sodium hydroxide, and 33\% $\mathrm{H}_{2} \mathrm{O}_{2}$ from El Nasr Pharmaceutical and Chemical Co. (Abu- Zaabal, Cairo, Egypt).

- Chromatographic grade ethanol used was purchased from LAB-SCAN Analytical Science (Dublin, Ireland).

\subsection{Solutions.}

- For HPLC

Stock standard solutions of FIN and TAM $(1 \mathrm{mg} / \mathrm{mL})$ in methanol and a working standard solutions of FIN $(0.5 \mathrm{mg} /$ $\mathrm{mL})$ and TAM $(0.4 \mathrm{mg} / \mathrm{mL})$ in the mobile phase were used.

\section{- For TLC}

Stock standard solutions of FIN and TAM $(1 \mathrm{mg} / \mathrm{mL})$ in methanol were used.

Preparation of Degradation Product of FIN in AcidStress Condition. Accurately weighed $20 \mathrm{mg}$ of pure FIN were dissolved in the least amount of methanol and mixed in a 20-mL 5-M HCL solution then left in a water bath for $3 \mathrm{~h}$ at $90{ }^{\circ} \mathrm{C}$. The solution was cooled at room temperature and neutralized by $\mathrm{NaOH}$ till $\mathrm{pH} 7$ and the solution was filtered. The filtrate was subsequently transferred into a $100-\mathrm{mL}$ beaker and evaporated to dryness at room temperature. The residue was dissolved in $90 \mathrm{~mL}$ methanol and transferred into a $100-\mathrm{ml}$ volumetric flask. The volume was completed with the same solvent to form a stock solution of degradation product equivalent to $200 \mu \mathrm{g} / \mathrm{mL}$.

Alkaline Degradation of FIN. The procedure under acid stress conditions was repeated using $5 \mathrm{M} \mathrm{NaOH}$. All procedures of neutralization and filtration were done as described in acid conditions.

Oxidation of FIN. Oxidation was performed by the use of $33 \% \mathrm{H}_{2} \mathrm{O}_{2}$. The same previous procedure was applied.

Stability Study of TAM. All the former procedures carried out on FIN (acid, alkaline, and oxidation degradation) were performed on TAM.

Laboratory Prepared Mixtures. Different aliquots of FIN and TAM were transferred from their working standard solutions into a series of 50-mL volumetric flasks. Then, aliquots of acid degradation product were added. The volume was 
completed to the mark with the mobile phase to prepare mixtures of different ratios of FIN, TAM, and acid degradation product of FIN.

\subsection{Procedures}

\subsubsection{Chromatographic Conditions}

(a) HPLC. Chromatographic separation was carried out at room temperature using a column Bondapak C18 (300 mm $\times$ $3.9 \mathrm{~mm}, 10-\mu \mathrm{m}$ particle size) and a mobile phase consisting of $0.04 \mathrm{M}$ ortho-phosphoric acid $(\mathrm{pH} 3.5 \pm 0.2)$ adjusted with triethylamine and acetonitrile $(50: 50, v / v)$. The mobile phase was filtered using a $0.45-\mu \mathrm{m}$ Millipore membrane filter and degassed by ultrasonic vibrations prior to use. The flow rate of the mobile phase was $1 \mathrm{~mL} / \mathrm{min}$. A volume of $20 \mu \mathrm{L}$ of each solution was injected, and the detector was adjusted at $215 \mathrm{~nm}$.

(b) TLC. Ten-microliter spots of each stock solution were spaced $1.5 \mathrm{~cm}$ apart from each other and were applied, $2 \mathrm{~cm}$ from the bottom edge of the plate. The plates were placed in a chromatographic tank previously saturated with the mobile phase that consists of toluene-ethanol-diethyl amine (8:2:1.5 by volume). The plate was left to develop by ascending chromatography through a distance of $16 \mathrm{~cm}$ and then dried at room temperature.

\subsubsection{Construction of Calibration Curve}

(a) HPLC method. Aliquots of FIN and TAM were separately transferred from their working standard solutions into a series of $25-\mathrm{mL}$ volumetric flasks. The volume was completed to the mark with the mobile phase to obtain $10-110 \mu \mathrm{g} / \mathrm{mL}$ FIN and $2-44 \mu \mathrm{g} / \mathrm{mL}$ TAM. Twenty-microliter triplicate injections were made for each concentration and chromatographed under the conditions described above. The peak area of each concentration was recorded and plotted against the corresponding concentration to obtain the calibration curves, and then, the regression equations of FIN and TAM were computed.

(b) TLC-densitometric method. Aliquots of FIN and TAM were separately transferred from their standard solutions into a series of $10-\mathrm{mL}$ volumetric flasks. The volume was completed to the mark with the methanol. Ten microliters of each solution were applied on the TLC plates by using a $25-\mu \mathrm{L}$ automatic syringe to obtain spots in the concentration range of $1.0-40.0 \mu \mathrm{g}$ per spot for FIN and $0.2-20.0 \mu \mathrm{g}$ per spot for TAM. Spots were spaced $1.5 \mathrm{~cm}$ apart from each other and $2 \mathrm{~cm}$ from the bottom edge. The spots were developed using a previously mentioned developing system, and then dried in air. The spots were scanned at $250 \mathrm{~nm}$ for FIN and $280 \mathrm{~nm}$ for TAM. The peak area of each concentration was plotted against the corresponding concentration to obtain the calibration curves, and then the regression equations of FIN and TAM were computed.

2.5.3. Application to Pharmaceutical Preparation. For analysis of commercial formulations, 10 capsules were emptied and mixed. A weight equivalent to 1 capsule $(5 \mathrm{mg}$ and $0.4 \mathrm{mg}$ of FIN and TAM, respectively) was taken and transferred into a $50-\mathrm{mL}$ volumetric flask. Then, $30 \mathrm{~mL}$ of methanol was added and sonicated for $15 \mathrm{~min}$, and the volume was completed to the mark and filtered. Analysis was done as previously mentioned under construction of calibration curves.

\section{Results and Discussion}

FIN and TAM are used together in a pharmaceutical formulation. The presented study involves a stability study of FIN, where an acid degradation product is present. We aimed to determine both FIN and TAM simultaneously and in the presence of the acid degradation product of FIN. HPLC and TLC techniques were used in the study. The degradation product of
FIN was isolated and investigated, and its structure was elucidated.

Stability Study of Finasteride. FIN was found to be liable to acid degradation and stable under alkaline or oxidative conditions. Complete degradation was achieved by treatment with $5 \mathrm{M} \mathrm{HCl}$ solution for $3 \mathrm{~h}$ at $90{ }^{\circ} \mathrm{C}$. FIN was degraded into one main degradation product. When alkaline $(5 \mathrm{~N}$ $\mathrm{NaOH})$ or oxidative $\left(33 \% \mathrm{H}_{2} \mathrm{O}_{2}\right)$ conditions were applied, no degradation was noticed.

Stability Study of Tamsulosin. TAM was found to be rather stable; when subjected to the same stress conditions as finasteride, no degradation was observed. A degradation of 3, 5 , and $2 \%$ was observed under acidic, alkaline, and oxidative conditions, respectively.

Structure Elucidation of Finasteride Acid Degradation Product. The IR spectrum of intact FIN (Figure 2a) showed a characteristic band at $1705 \mathrm{~cm}^{-1}$ corresponding to a carbonyl group [17]. The spectrum of acid degradation product of FIN showed an additional broad band at $3428 \mathrm{~cm}^{-1}$ corresponding to a hydroxyl group as shown in Figure $2 \mathrm{~b}$. This band is not present in the intact FIN spectrum.

In the MS chart of FIN (Figure 3a), the parent peak was identified at $\mathrm{m} / \mathrm{z}=372.6$ (corresponding to molecular weight of FIN). The mass ion peak $\mathrm{m} / \mathrm{z}$ at 318.2 for the degradation product was identified [18] as shown in Figure 3b.

HPLC Method. Since no method has been reported in the literature for the determination of FIN in the presence of its acid degradation product, it was thought necessary to develop a validated stability-indicating HPLC method for the determination of FIN and TAM in bulk material and pharmaceutical preparation. A satisfactory separation between FIN and its degradation was obtained with acetonitrile$0.04 \mathrm{M}$ ortho-phosphoric acid $(\mathrm{pH} 3.5 \pm 0.2$ adjusted with triethylamine) $(50: 50, v / v)$ at flow rate $1 \mathrm{~mL} / \mathrm{min}$, with UV detection at $215 \mathrm{~nm}$, and at $25 \pm 1{ }^{\circ} \mathrm{C}$. Several trials were carried out to optimize the HPLC method, to obtain a good resolution between the cited components. These trials involved are the following.

Effect of Changing Mobile Phase Composition. The influence of the amount of organic solvent on the peak shape and retention time of the components was investigated using different ratios of the proposed components. Addition of high percentage of acetonitrile and low percentage of buffer brought about inadequate resolution between the FIN and its degradation product. Increasing the amount of buffer led to interference between peaks, and this high buffer percentage increased the run time, which made the proposed HPLC method of analysis time and cost consuming. A satisfactory separation between FIN, its degradation product, and TAM was obtained with acetonitrile-buffer $(50: 50, v / v)$.

Effect of Mobile Phase pH. The $\mathrm{pH}$ of the mobile phase has a great effect on the shapes of the separated peaks. The use of $\mathrm{pH} 3.5$ gave the best separation, and increasing $\mathrm{pH}$ resulted in bad separation and low resolution between the components. Within a $\mathrm{pH}$ range of 3.3-3.7, no significant impact was observed on the critical chromatographic parameters (resolution, peak shape, tailing, and retention time).

Instrumental Conditions. Several wavelengths were tried $(210,215,230$, and $254 \mathrm{~nm})$ for detection of resolved components. The most suitable wavelength was $215 \mathrm{~nm}$, which gave reasonable sensitivity. In addition, the mobile phase was delivered at different rates $(0.8,1$, and $1.5 \mathrm{~mL} / \mathrm{min})$, and the optimum was $1.0 \mathrm{~mL} / \mathrm{min}$, which provided complete separation with good resolution and suitable analysis run.

The retention times were $4.0 \pm 0.2 \mathrm{~min}, 5.0 \pm 0.2 \mathrm{~min}$, and $9.0 \pm 0.2$ for TAM, degradation product, and FIN, respectively (Figure 4). The mean percentage recovery of pure samples 


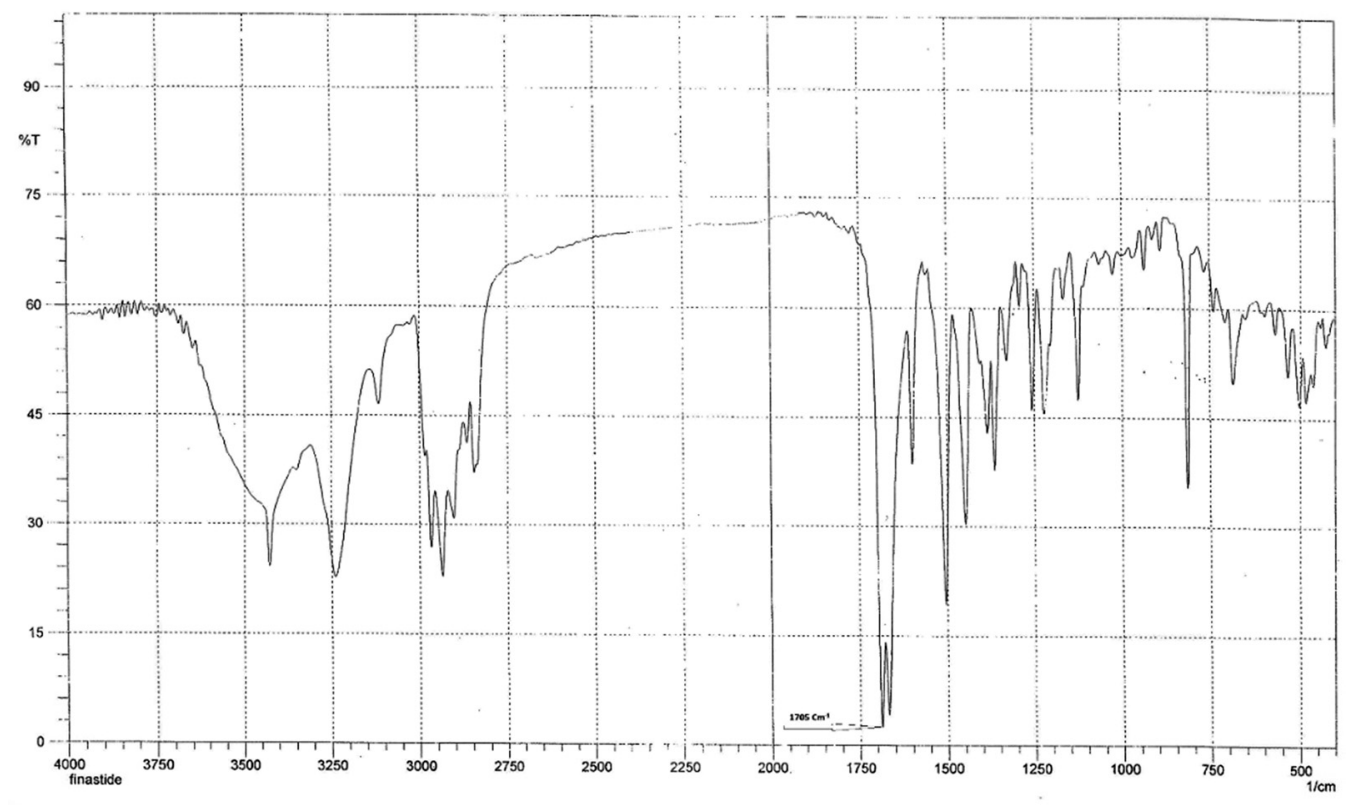

(a)

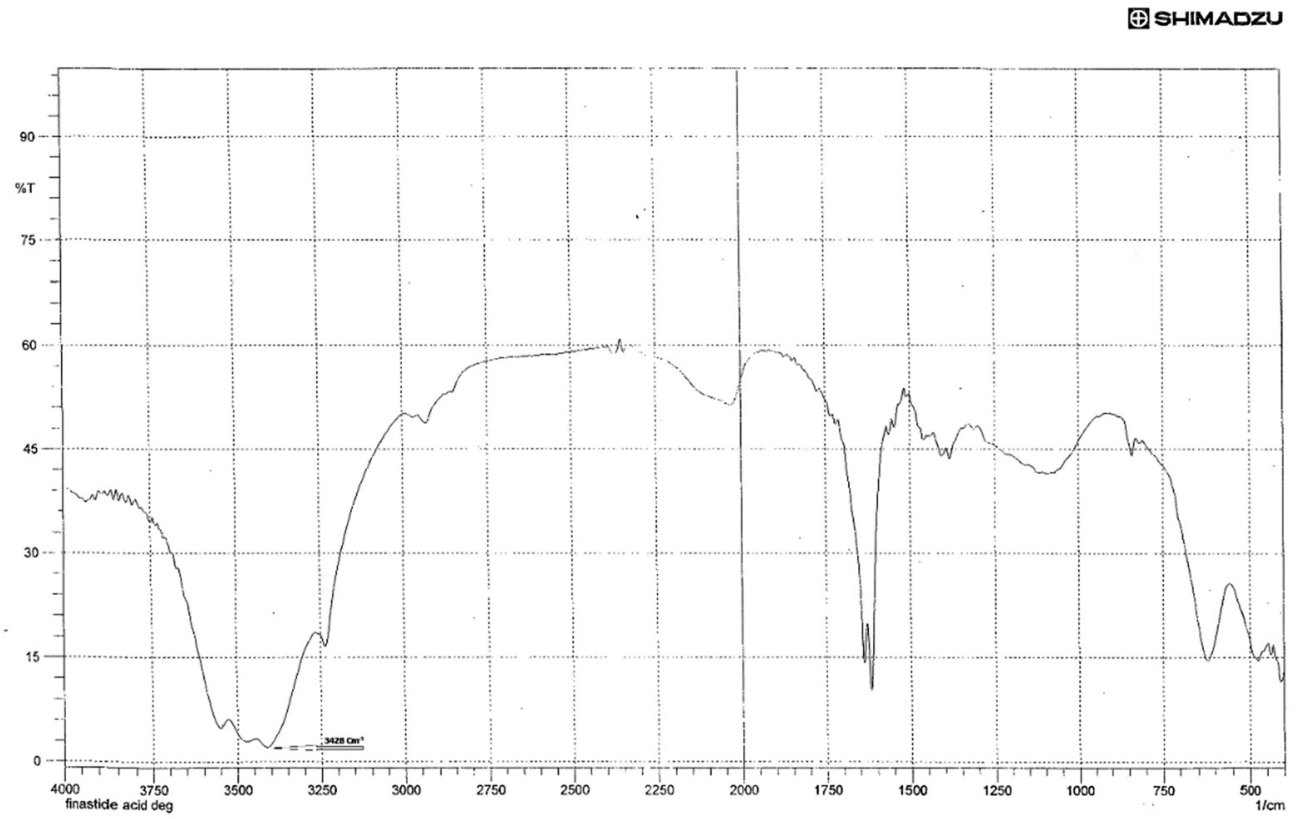

(b)

Figure 2. IR spectra of finasteride (a) and its acid degradation product (b)

was found to be 99.88 and $99.72(n=6)$, using the following regression equations:

For FIN: $P=45.394 C-15.441$

$$
r=0.9996
$$

For TAM: $P=43.194 C+20.251$

$$
r=0.9999
$$

where $P$ is the peak area, $C$ is the concentration in $\mu \mathrm{g} / \mathrm{mL}$, and $r$ is the correlation coefficient. To assess the accuracy of the results, different pure samples of the studied drugs were analyzed by the suggested method, and the concentrations were calculated from the corresponding regression equation.
System suitability parameters of the proposed HPLC method were calculated according to the United States Pharmacopeia (USP) [16], showing good resolution, selectivity, and symmetrical peaks (Table 1a). The proposed method was found to be more advantageous by better resolution, higher capacity, and being much more sensitive than the reported one [14]. The validation of this method was applied according to the International Conference on Harmonisation (ICH) [19] guidelines. The results are shown in Table 2.

The proposed HPLC method could be used as stability-indicating method for the determination of FIN and TAM in laboratory-prepared mixtures in the presence of up to $90 \%$ of acid degradation product of FIN with a mean percentage recovery 


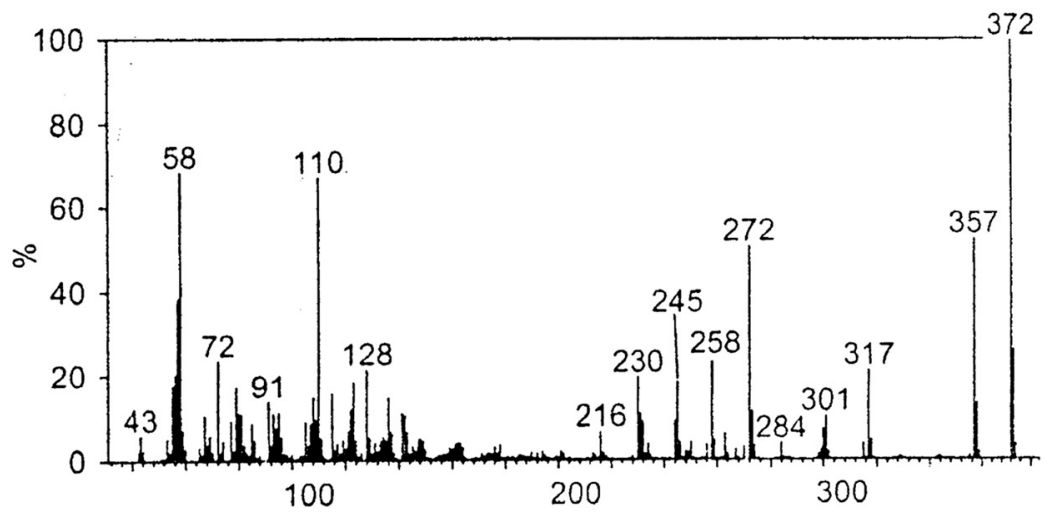

(a)

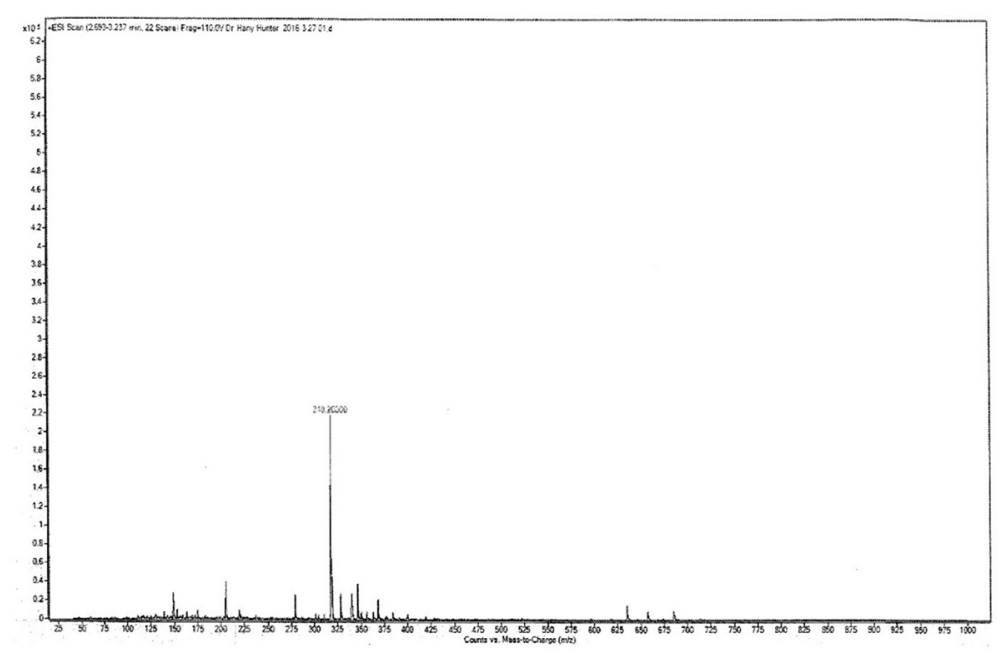

(b)

Figure 3. Mass spectra of finasteride (a) and its acid degradation product (b)

of $100.62 \pm 1.21$ and $100.48 \pm 1.10$ for FIN and TAM, respectively (Table 3 ). Moreover, the accuracy of the proposed method was evaluated by comparing it with a reported HPLC method [14]. The calculated $t$ - \& $F$-values were less than the tabulated ones (Table 4), indicating that no significant difference was observed regarding both accuracy and precision at $95 \%$ confidence level between the two methods.

TLC Method. Several mobile phases were tested to accomplish good separation of FIN, TAM, and the degradation product of FIN. Using the developing system, namely, toluene-ethanol-diethylamine ( $8: 2: 1.5$, by volume) and silica gel $60 \mathrm{~F}_{254}$ aluminum-coated plates as a stationary phase, better separation was attained for FIN and TAM with $R_{\mathrm{F}}$ values of 0.57 and 0.64 , respectively. Despite rather near $R_{\mathrm{F}}$ values for both drugs, they have been fully separated on the TLC plates (Figure 5). The spots of FIN and TAM have been measured at $250 \mathrm{~nm}$ and $280 \mathrm{~nm}$, respectively. The mean percentage recovery of pure samples was found to be 101.04 \pm 1.77 and $99.77 \pm 1.77(n=6)$ using the following regression equation:

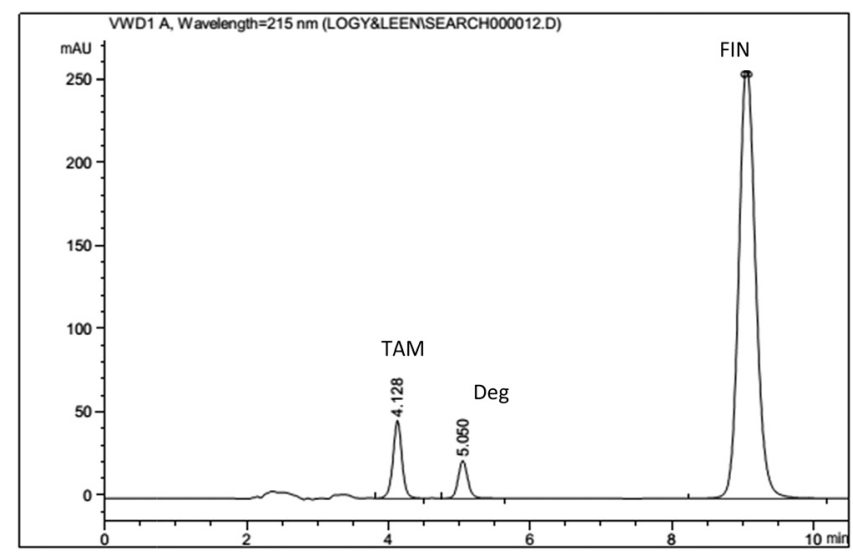

Figure 4. Typical HPLC chromatogram of FIN $(100 \mu \mathrm{g} / \mathrm{mL})$, acidic degradation product $(8 \mu \mathrm{g} / \mathrm{mL})$, and TAM $(8 \mu \mathrm{g} / \mathrm{mL})$ 
Table 1. System suitability parameters of the proposed (a) HPLC and (b) TLC-densitometric methods

\begin{tabular}{|c|c|c|c|c|c|c|}
\hline Parameter & TAM & & FIN deg & & FIN & Reference value \\
\hline \multicolumn{7}{|l|}{ (a) } \\
\hline Resolution (Rs) & & 4.02 & & 12.16 & & $R>1.5$ \\
\hline Selectivity $(\alpha)$ & & & 1.22 & & 1.79 & $>1$ \\
\hline Tailing factor $(T)$. & 0.98 & & 1.12 & & 1.13 & 1 \\
\hline Capacity factor $(k)$ & 3.55 & & 4.61 & & 9.05 & $1-10$ \\
\hline$N$ & 5629 & & 7278 & & 7395 & Increases with efficiency of separation \\
\hline Retention time $(\min \pm 0.2)$ & 4.12 & & 5.05 & & 9.05 & \\
\hline \multicolumn{7}{|l|}{ (b) } \\
\hline Parameter & TAM & & FIN & & & Reference value \\
\hline Resolution (Rs) & & 1.2 & & & & $R>1.5$ \\
\hline Selectivity $(\alpha)$ & & 1.34 & & & & $>1$ \\
\hline Tailing factor $(T)$ & 0.96 & & 1.04 & & & 1 \\
\hline$R_{\mathrm{F}}$ & 0.54 & & 0.6 & & & \\
\hline
\end{tabular}

Table 2. Validation parameters of the proposed methods for the determination of tamsulosin hydrochloride and finasteride

\begin{tabular}{|c|c|c|c|c|}
\hline \multirow[t]{2}{*}{ Parameter } & \multicolumn{2}{|c|}{ Finasteride } & \multicolumn{2}{|c|}{ Tamsulosin $\mathrm{HCl}$} \\
\hline & HPLC & TLC & HPLC & TLC \\
\hline $\begin{array}{l}\text { Range } \\
\text { Linearity }\end{array}$ & $10.0-110.0(\mu \mathrm{g} / \mathrm{mL})$ & $1.0-40.0(\mu \mathrm{g}$ per spot) & $2.0-44.0(\mu \mathrm{g} / \mathrm{mL})$ & $0.2-20.0(\mu \mathrm{g}$ per spot $)$ \\
\hline Slope & 45.39 & $\begin{array}{c}\text { Co. } 1-3.284 \\
\text { Co. } 2392.4\end{array}$ & 43.19 & $\begin{array}{c}\text { Co. } 1-46.16 \\
\text { Co. } 21677\end{array}$ \\
\hline Intercept & -15.44 & 244.28 & 20.25 & 949.33 \\
\hline Correlation coefficient & 0.9996 & 0.9990 & 0.9999 & 0.9990 \\
\hline Repeatability $^{a}$ & 0.27 & 1.09 & 0.80 & 1.67 \\
\hline Intermediate precision $^{b}$ & 1.04 & 0.50 & 0.89 & 1.09 \\
\hline Specificity and selectivity Mean \pm SD & $100.62 \pm 1.22$ & $100.17 \pm 1.69$ & $100.48 \pm 1.11$ & $100.21 \pm 1.88$ \\
\hline $\mathrm{LOD}(\mu \mathrm{g} / \mathrm{mL})$ & 2.61 & 1.13 & 0.58 & 0.14 \\
\hline LOQ $(\mu \mathrm{g} / \mathrm{mL})$ & 7.92 & 3.38 & 1.76 & 0.42 \\
\hline Robustness & $99.70 \pm 0.91$ & $99.65 \pm 1.21$ & $100.95 \pm 1.17$ & $99.56 \pm 1.34$ \\
\hline
\end{tabular}

For FIN : $\quad P=-3.284 C^{2}+392.4 C+244.28 \quad r=0.9990$

For TAM : $P=-46.16 C^{2}+1677 C+949.33 \quad r=0.9990$

Table 3. Determination of FIN and TAM in laboratory-prepared mixtures by the proposed method

\begin{tabular}{lccc}
\hline Sample No. & Degradation (\%) & \multicolumn{2}{c}{ \%Recovery $^{a}$} \\
\cline { 3 - 4 } & & FIN & TAM \\
\hline 1 & 10 & 101.26 & 100.76 \\
2 & 20 & 99.08 & 101.82 \\
3 & 30 & 100.50 & 98.86 \\
4 & 40 & 101.67 & 100.53 \\
5 & 50 & 101.95 & 99.10 \\
6 & 70 & 98.84 & 100.9 \\
7 & 90 & 101.05 & 101.39 \\
Mean \pm SD & & $100.62 \pm 1.21$ & $100.48 \pm 1.10$ \\
\multicolumn{2}{c}{${ }^{a}$ Average of 3 experiments. } & & \\
\hline
\end{tabular}

Table 4. Statistical comparison of the results obtained between the proposed HPLC and TLC methods and a reported method

\begin{tabular}{lcccccccc}
\hline & \multicolumn{3}{c}{ FIN } & & \multicolumn{3}{c}{ TAM } \\
\hline Parameter & \multicolumn{2}{c}{ Proposed } & Reported & & Proposed & Reported \\
\cline { 2 - 3 } & HPLC & TLC & & {$[14]$} & & HPLC & TLC & {$[14]$} \\
\hline Mean & 98.31 & 100.5 & 98.11 & & 100.42 & 99.7 & 99.84 \\
S.D. & 1.44 & 1.19 & & 1.88 & & 1 & 1.74 & 1.47 \\
Variance & 2.09 & 1.42 & & 3.56 & & 1.01 & 3.03 & 2.18 \\
$N$ & 6 & 6 & 6 & & 6 & 6 & 6 \\
$F$-value $(5.05)$ & 1.7 & 2.28 & & & 2.15 & 1.33 & \\
Student's $t$-test & 2.20 & 0.24 & & & 0.79 & 0.98 & \\
$(2.228)$ & & & & & & &
\end{tabular}

(2.228)

Values in parenthesis are the theoretical $t$ and $F$-values at $p=0.05$. where $C$ is the concentration in $\mu \mathrm{g} / \mathrm{mL}$ and $r$ is the correlation coefficient. To assess the accuracy of the results, different pure samples of the studied drugs were analyzed by the suggested method, and the concentration were calculated from the corresponding regression equation. System suitability parameters for the TLC-densitometric method are presented in Table $1 \mathrm{~b}$. The accuracy of the proposed method was evaluated by comparing it with a reported HPLC method [14]. The calculated $t$ - \& F-values were less than the tabulated

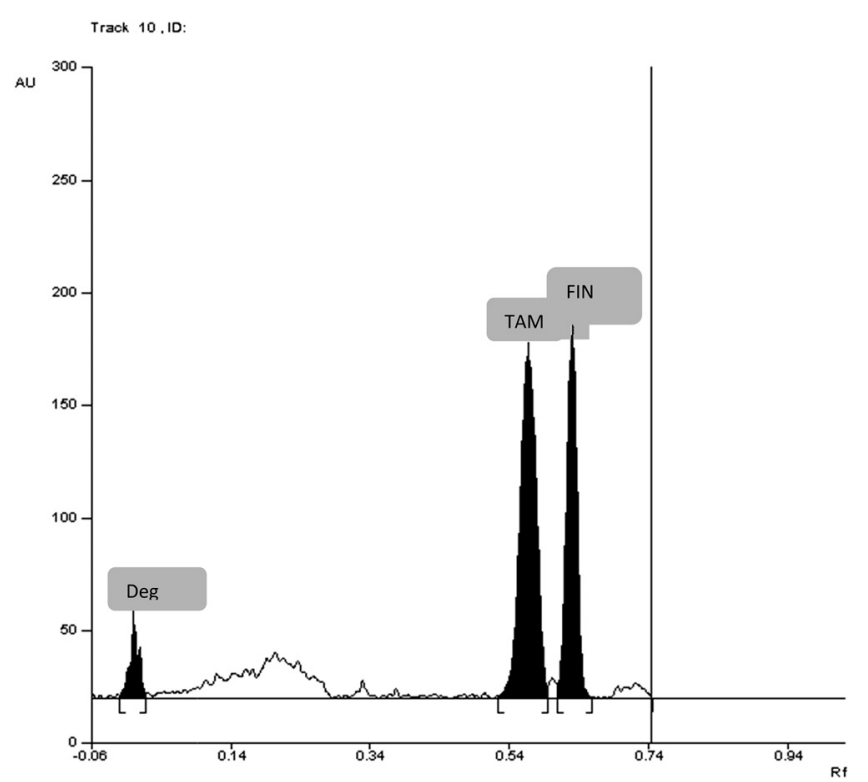

Figure 5. Two-dimensional densitogram of finasteride, tamsulosin $\mathrm{HCl}$, and the degradation product of finasteride using toluene-ethanol-diethylamine (8:2:1.5, by volume) as a developing system 
one (Table 4), indicating that no significant difference was observed.

The validation of the method was applied according to the ICH [19] guidelines. The results are shown in Table 2.

\section{Conclusion}

The proposed work provided simple, sensitive, selective, and accurate HPLC and TLC-densitometric methods for determination of FIN and TAM in the presence of the degradation product of FIN in bulk powder and pharmaceutical formulation without interference from the excipients. The proposed methods were validated according to the ICH guidelines and could be used for routine analysis FIN and TAM in quality control laboratories, where economy and time were essential.

\section{References}

1. Budavari, S. The Merck index $14^{\text {th }}$ Ed., Merk and Co. Inc., white house station, NJ 1996.

2. Sweetman, Ed. S. C. Martindale The Complete Drug Reference $35^{\text {th }}$ ed., Pharmaceutical Press, The Royal Pharmaceutical Society, London 2005.

3. Hardman, J. G.; Limbard, L. E.; Gilman, A. G. Goodman Gilman's: The pharmacological Basis of Therapeutics $9^{\text {th }}$ ed McGraw-Hill, NewYork, 2001.

4. Keski Rahkonen, P.; Parssinen, O.; Leppanen, E.; Mauriala, T.; Lehtonen, M.; Auriola, S.; Determination of tamsulosin in human aqueous humor and serum by liquid chromatography electrospray ionization tandem mass spectrometry J. Pharm. Biomed. Anal. 2007, 43, 606-612.

5. Din, L.; Li, L.; Tao, P.; Yang, J.; Zhang, Z.; Quantitation of tamsulosin in human plasma by liquid chromatography electrospray ionization mass spectrometry J. Chromatogar. B. 2002, 767, 75-81.

6. Ramakrishna, N. V.; Vishwottam, K. N.; Manoj, S.; Koteshwara, M.; Wishu, S.; Varma, D. P.; Rapid, simple and highly sensitive LC-ESI-MS/MS method for the quantification of tamsulosin in human plasma Biomed. Chromatogr. 2005, 19, 709-719.
7. Soeishi, Y.; Kobori, M.; Kobayashi, S.; Higuchi, S.; Sensitive method for the determination of tamsulosin in human plasma using high performance liquid chromatography with fluorescence detection $J$. Chromatogr. 1990, 533 , 291-296.

8. Sangita, A.; Veeran, K.; Amlan, S.; Debotri, G.; Uttam, B.; Tapas, C.; Tapan, P.; Simultaneous determination of tamsulosin and dutasteride in human plasma by LC-MS-MS, J. Chromatogr. 2008, 67, 893-903.

9. Constanzer, M. L.; Chavez, C. M.; Matuszewski, B. K.; Picogram determination of finasteride in human plasma and semen by high performance liquid chromatography with atmospheric pressure chemical ionization tandem mass spectrometry J. Chromatogr. 1994, 658, 281-287.

10. Guo, F. Q.; Huang, L. F.; Wong, K. P.; Dai, Y.H.; Li, Y. W.; Liang, Y. Z.; Huang, K. L.; Zhong, K. J.; Wu, M. J. A rapid, simple, specific liquid chromatographic electrospray mass spectrometry method for the determination of finasteride in human plasma and its application to pharmacokinetic study $J$. Pharm. Biomed. Anal. 2007, 43, 1507-1513.

11. Xiaohong, C.; Erin, R. G.; Douglas, K. P.; William, D. F.; Development and validation of an LC-MS assay for finasteride and its application to prostate cancer prevention trial sample analysis J. Chromatogr. Sci. 2008, 46, 356-361.

12. Ptacek, P.; Macek, J.; Klima, J.; Determination of finasteride in human plasma by liquid- liquid extraction and high performance liquid chromatography J. Chromatogr. 2000, 738, 305-310.

13. Basavaiah, K.; Somashekar, B. C.; Determination of finasteride in tablets by high performance liquid chromatography $E-J$. Chem. 2007, 4, 109-116.

14. Nasare, M. K.; Satish, J.; Amrohi, S. H.; Harshini, S.; Kumar, M. Simultaneous determination of finasteride and tamsulosin in combined dosage form by using RP-HPLC method J. Liq. Chromatogr. Rel. Tech. 2014, 37, 1176-1186.

15. Sindhura, M.; Raghavi, K.; Prashanthi, R.; Nalluri, B. N.; Simultaneous estimation of finasteride and tamsulosin hydrochloride in combined dosage form by using RP-HPLC-PDA method J. Appl. Pharm. Sci. 2012, 2, 203-209.

16. The United States Pharmacopeia and National Formulary, USP 37-NF 32, U.S. Pharmacopeial Convention, Rockville, MD, 2014.

17. Dash, D. C. Analytical Chemistry New Delhi, India, 2011, p. 433.

18. , Hoffmann, E.de; Stroobant, V. Mass Spectrometry: Principles and Application John Wiley \&Son, $3^{\text {rd }}$ edition, New York, USA, 2007.

19. ICH, Q1A (R2), Stability Testing of New Drug Substances and Products, Q2 (R1) Validation of Analytical Procedures: Text and Methodology, International Conference on Harmonization, IFPMA, Geneva, Switzerland, (2003, 2005). 